\title{
O QUE AS CRIANÇAS PENSAM SOBRE A INVESTIGAÇÃO?
}

\author{
Amanda Cristina Rasche ${ }^{1}$ \\ Jacqueline Silva da Silva ${ }^{2}$
}

\begin{abstract}
Resumo: O presente artigo é resultado da pesquisa "A representação do olhar da criança sobre a investigaçáo", desenvolvida na Universidade do Vale do Taquari - Univates e, com o apoio da Fundação de Amparo à pesquisa do estado do Rio Grande do Sul - FAPERGS. A pesquisa teve como objetivo compreender, através de desenhos e escritas criativas de crianças da Educação Infantil e do Ensino Fundamental, o que elas entendem por investigação. Trabalhamos dentro do estudo com a premissa de que a investigação não se restringe apenas a atividades de laboratórios, mas, também, a simples atitudes do nosso cotidiano que nos instigam a explorar e questionar sobre os objetos que estão ao nosso redor (SILVA; BEUREN; LORENZON, 2016). O estudo seguiu uma abordagem qualitativa, levando em consideração crenças, valores, questóes mais subjetivas dos indivíduos (MINAYO, 2011). O contexto da pesquisa foram duas escolas da rede pública de ensino do município de Lajeado/RS/BRA, sendo uma da Educação Infantil e a outra do Ensino Fundamental. Os dados analisados foram desenhos, escritas criativas e falas das crianças, sendo esses, materiais decorrentes de cinco situaçóes de aprendizagem desenvolvidas com as crianças. Como resultados, identificou-se que parte das crianças observa a ciência como algo inacessível, que só faz ciência os cientistas, enquanto outras, demonstram se enxergarem como cientistas. Por isto, acredita-se na importância de trabalhar a estratégia investigativa dentro das escolas, pois ela oportuniza as crianças a serem protagonistas da sua própria aprendizagem e, capazes de romperem com essa visão individualista e elitista da ciência.
\end{abstract}

Palavras-chave: Investigação. Protagonismo Infantil. Educação Infantil. Ensino Fundamental.

\section{WHAT DO CHILDREN THINK ABOUT AN INVESTIGATION?}

Abstract: This article is the result of the research "The representation of the child's view on research" developed at the University of Vale do Taquari - Une and, with the support of the Amparo Foundation for research in the state of Rio Grande do Sul - FAPERGS. The research aimed to

1 Graduanda de Psicologia e Bolsista de Iniciação Científica da Universidade do Vale do Taquari Univates. Email: amanda.rasche@universo.univates.br

2 Doutora em Educação - UFRGS, docente do curso de Pedagogia e do Programa de Pós-Graduação Mestrado e Doutorado em Ensino e em Ensino de Ciências Exatas, na Universidade do Vale do Taquari - Univates. Email: jacqueh@univates.br 
understand through drawings and creative texts of children from kindergarten and elementary school, or what they understand an investigation. We work within a study with the premise that the investigation does not restrict only the activities of laboratories, but also, simple daily attitudes that instigate to explore and question about the objects that are around (SILVA; BUREN; LORENZO, 2016). The study followed a qualitative approach, taking into account the beliefs, values, more subjective issues of individuals (MINAYO, 2011). The context of the research was two public schools in the municipality of Lajeado/RS/BRA, one of which is Early Childhood Education and the other of Elementary Education. The analyzed data were drawings, creative writings, and children's speeches, being these, materials of five learning situations learned with children. As the results, identified as part of the children, observe a science as something inaccessible, which also makes science for scientists, while others demonstrate how to see as the sciences. For this reason, we believe in the importance of working with an investigative strategy within schools, as it is an opportunity for children to be protagonists of their learning and, capable of breaking with this individual and elitist view of science.

Keywords: Investigation. Child Protagonism. Early Childhood Education. Elementary School.

\section{INTRODUÇÃO}

O presente artigo é resultado da pesquisa intitulada "A representação do olhar da criança sobre a investigação", que foi subsidiado pela Universidade do Vale do Taquari - Univates e, com apoio da Fundação de Amparo à pesquisa do Estado do Rio Grande do Sul - FAPERGS. Por meio do estudo, buscou-se compreender através de desenhos, escritas criativas e falas de crianças da Educação Infantil e do Ensino Fundamental, o que elas entendem por investigação.

Consideramos dentro desta pesquisa, a investigação, como um dos princípios do Planejamento no enfoque Emergente, os quais são desenvolvidos no projeto educativo das escolas de Educação Infantil, localizadas na cidade de Reggio Emilia/ Italia (SILVA, 2011). A investigação é vista, como uma atitude simples do cotidiano, a qual envolve a resolução de problemas e nos instiga a questionar e a explorar o que está ao nosso redor (SILVA; BEUREN; LORENZON, 2016).

A abordagem do Planejamento, no Enfoque Emergente, é conceituada por Rinaldi (1999) como uma ferramenta de trabalho, utilizada pelos professores para apresentar objetivos educacionais gerais e que não delimitam objetivos específicos para cada atividade. Ao contrário disso, trabalham com objetivos flexíveis que são adaptados aos interesses e às necessidades expressadas pelas crianças, ao longo dos diferentes momentos do cotidiano da escola de Educação Infantil.

Na perspectiva do Planejamento Emergente, a criança é vista como talentosa, capaz de criar e explorar significados do mundo que a cerca em meio ao seu processo de conhecimento. Dessa forma, ao considerar a criança como protagonista da sua aprendizagem e colocá-la no centro da açáo pedagógica, passamos a entender que o conhecimento não acontece pela transmissão do saber por parte do professor, mas que a aprendizagem é construída por meio das trocas entre eles (SILVA, 2011). 
Nesse sentido, apresentaremos a seguir, a importância de utilizarmos a investigação como estratégia de ensino que impulsiona o protagonismo infantil dentro do ambiente escolar e, como o professor pode oportunizá-la neste contexto.

\section{A INVESTIGAÇÃO COMO ESTRATÉGIA DE ENSINO IMPULSIONADORA DO PROTAGONISMO INFANTIL NAS ESCOLAS}

Em meados do século XIX e até mesmo do XX, a imagem que se tinha sobre a criança era que ela não passava de um sujeito vazio, sendo comparada à concepção de tábula rasa, que significa "folha em branco". Desta forma, acreditava-se que as crianças não tinham capacidade própria de observar e interpretar o mundo, por isto, deveriam ser instruídas. Com o passar do tempo, essa visão foi se modificando e hoje em dia, parece impossível não reconhecer as crianças como indivíduos ativos e participantes da sua própria aprendizagem (SILVA; BEUREN; LORENZON, 2016).

Para Chassot (1995), existe uma relação entre a prática pedagógica e a concepçáo que os professores possuem a respeito dos seus alunos. No entanto, quando os educadores olham para os mesmos, fundamentados na concepção de tábula rasa, "serão organizadas atividades, preferencialmente dirigidas e organizadas pelo professor, dada a incapacidade e a impotência pressuposta à criança" (SILVA; BEUREN; LORENZON, 2016, p. 15). Ao contrário disso, quando as crianças são vistas como protagonistas das suas aprendizagens, entende-se que elas não devem ser treinadas, mas sim, incentivadas a expressarem suas ideias, seus interesses e necessidades, sendo partícipes dos processos que envolvem o cotidiano da escola.

Nesse sentido, acreditamos que a investigação seja uma estratégia de ensino que oportunize as crianças ao desenvolvimento do protagonismo. E, para o desenvolvimento da estratégia, cabe ao professor oportunizar situaçóes de aprendizagem, as quais permitam às crianças construírem seus próprios recursos para resolverem as dificuldades que seráo encontradas ao longo do processo investigativo (SILVA; BEUREN; LORENZON, 2016).

Como forma de organização desse processo, Lorenzon (2018), o divide em quatro etapas: a elaboração de questionamentos, a formulação de hipóteses, a construção dos argumentos e a comunicação dos achados. Na primeira etapa, o professor busca identificar os assuntos em que as crianças possuem dúvidas e a partir deles, incentivá-las a criarem perguntas que nortearão o desenvolvimento do estudo. Na segunda etapa, o professor passa a formular hipóteses com as crianças, a partir dos conhecimentos que as mesmas já possuem em relação ao que desejam saber sobre determinados assuntos, estimulando-as a buscar respostas aos seus questionamentos. A terceira etapa consiste na elaboração dos argumentos, isto é, efetuar e apresentar às crianças dados que corroboram com as alegaçóes feitas. E, após a construção dos argumentos, se inicia o compartilhamento do que foi encontrado. 
Diante do exposto, reitera-se a importância do professor nessas etapas, uma vez que, de acordo com Ferraz e Sasseron (2017, p. 04) "o ensino por investigação só será de fato investigativo se o professor promover condiçóes para que ele ocorra". Desse modo se faz necessária a escuta atenta do professor para que as crianças se sintam acolhidas em compartilhar seus interesses, curiosidades e, também, que através dessa escuta impulsione as mesmas a buscarem pelas respostas de suas indagaçôes, permitindo a elas o protagonismo infantil.

\section{DELINEAMENTO METODOLÓGICO}

O presente estudo segue a abordagem qualitativa que de acordo com Minayo (2011), leva em consideração questôes mais subjetivas do indivíduo, como crenças, valores, atitudes, permitindo-nos conhecê-lo na sua essência.

O locus da pesquisa foram duas escolas da rede pública de ensino, localizadas no município de Lajeado, interior do Rio Grande do Sul. Em uma das escolas, a pesquisa foi realizada com uma turma da Educação Infantil, composta por 23 crianças da faixa etária de 5 a 6 anos e, na outra, as situaçóes de aprendizagem foram desenvolvidas com uma turma do segundo ano, do Ensino Fundamental, composta por 22 crianças, com idades entre 7 a 8 anos.

É importante salientar que todos os envolvidos no estudo, desde os professores das turmas até os responsáveis pelas crianças, estiveram cientes das práticas das atividades realizadas e assentiram o estudo, assinando o Termo de Consentimento Livre e Esclarecido - TCLE. Embora os responsáveis pelas crianças tenham assinado o termo, destaca-se que as crianças também deram o seu consentimento, através da manifestação de diferentes linguagens.

A coleta dos dados ocorreu por meio de desenhos, de escritas criativas e da fala das crianças. Essas documentaçóes, assim como as falas, emergiram de rodas de conversa através de cinco situaçốes de aprendizagem, elaboradas e desenvolvidas pelos pesquisadores que foram ao campo do estudo. Os dados gerados foram analisados através de uma aproximação com a técnica da Análise de Conteúdo, proposto por Bardin (2012), a qual propóe uma interpretação minuciosa do conteúdo das mensagens manifestas, buscando por trás delas uma compreensão mais aprofundada. A análise das mensagens nos proporcionou a criaçáo de categorias, através de critérios de semelhança de conteúdo para, em seguida, realizarmos a interpretação e articulação teórica. Em decorrência da análise, formaram-se duas categorias: Investigação como atividade restrita e Investigaçáo como atividade abundante.

$\mathrm{Na}$ sequência, serão apresentados os resultados da análise realizada a partir dos desenhos, das escritas criativas e das falas das crianças, discorrendo sobre o que elas entendem por investigação. 


\section{ANÁLISE DOS DADOS}

\section{Investigaçáo como atividade restrita}

Ao olhar para os desenhos e para as escritas criativas das crianças, percebemos que parte das crianças compreende a investigação como uma atividade restrita, podendo ser realizada apenas por pessoas extremamente inteligentes, que se utilizam de objetos e vestimentas específicas para isso. Algumas dessas características, que predominam no entendimento das crianças sobre a investigação, podem ser vistas no desenho a seguir.

FIGURA 1- Aluno da Educação Infantil.

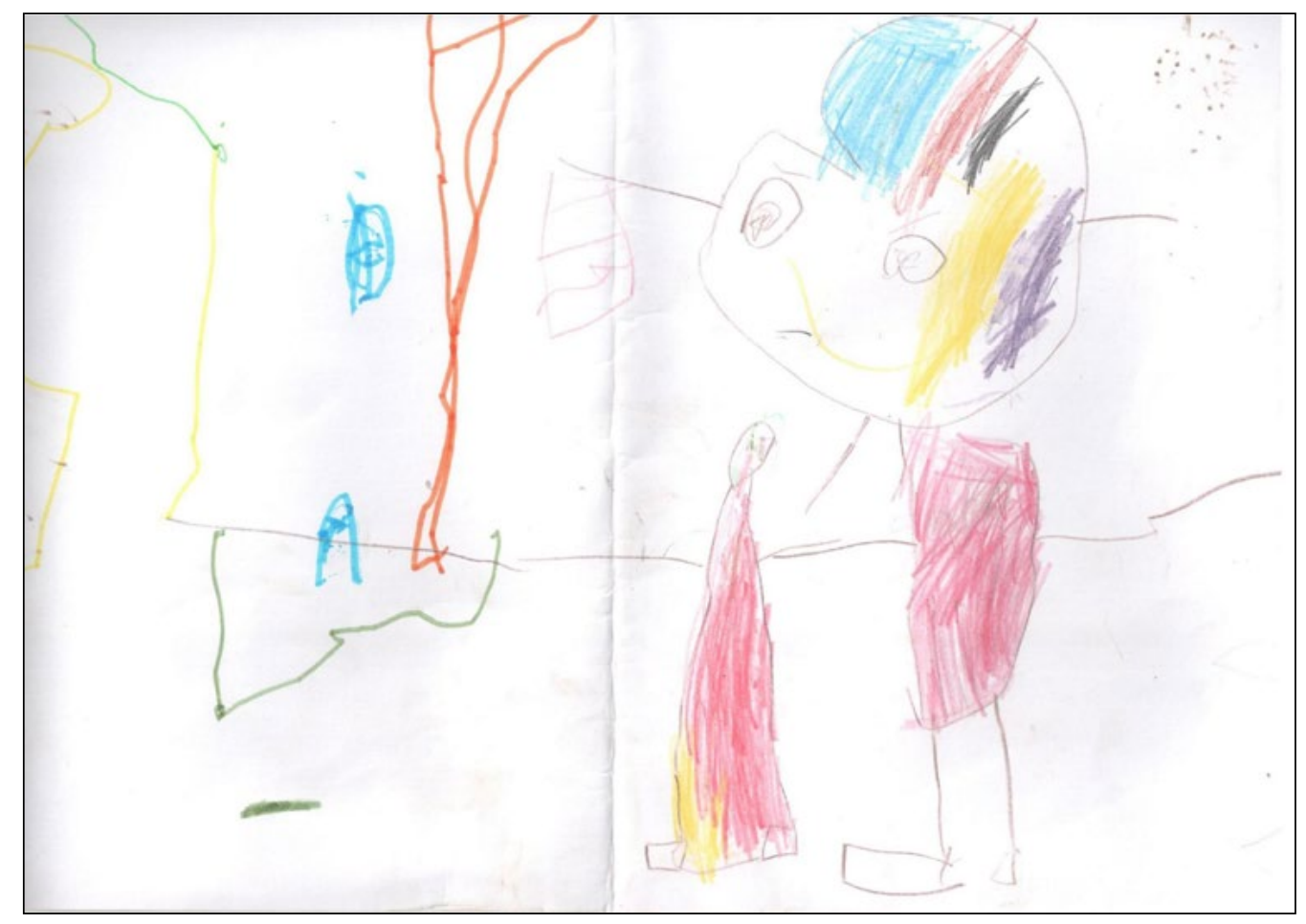

A criança, quando questionada pelos pesquisadores a respeito do desenho, relata ter desenhado a sua imagem e a de um cientista, dentro de um local fechado. Chamou-nos a atenção que os dois personagens ilustrados são bastante diferentes, uma vez que o cientista é representado como um indivíduo alto, possuindo uma cabeça desproporcional ao tamanho do corpo e a criança aparece representada como um ser pequeno, bem menor que a figura do cientista.

Ao observar o desenho (figura 1), é possível compreender o entendimento dessa criança a respeito da investigaçáo. Isso porque, o fato do cientista ter uma cabeça grande, parece representar o tamanho da inteligência que o menino acredita 
que o cientista deva possuir. Dessa forma, sugere-se que o entendimento que a criança possui sobre a investigação assemelha-se às ideias abordadas por uma das visôes distorcidas da ciência, a individualista e elitista.

Esta concepção, segundo Cachapuz (2005), faz parte de um grupo de visóes empobrecidas da ciência, que transmite erroneamente a forma como se constroem os conhecimentos científicos. Especificamente, a visão individualista e elitista, considera a ciência como algo que provém de "gênios", ou seja, que é dominada apenas por indivíduos extremamente inteligentes.

Além do desenho apresentado na figura 1, aspectos relacionados a esta visão também são encontrados na escrita criativa apresentada logo abaixo.

FIGURA 2 - Aluno do Ensino Fundamental.

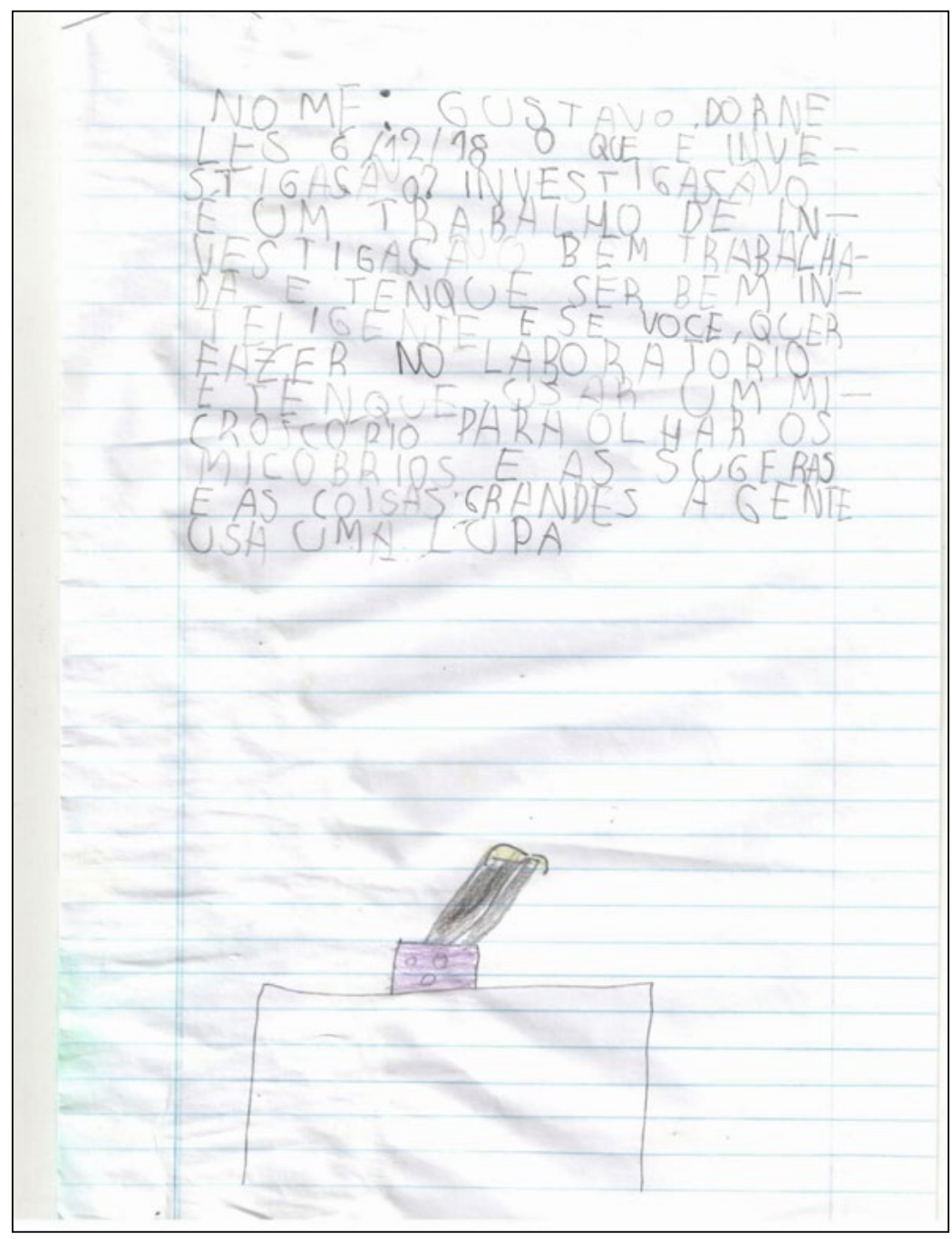


Através da escrita criativa, que segundo Carnaz (2013), é uma das melhores maneiras de estimular a imaginação nas crianças, o aluno relata que "tem que ser bem inteligente" para investigar e que "tem que usar um microscópio para olhar os micóbrios" e que para ver "as sugeras e as coisas grande a gente usa uma lupa". No entanto, entende-se que tanto essa criança como a anterior, veem o cientista conforme a concepção individualista e elitista descreve-o, como um indivíduo que trabalha em laboratório, veste jaleco branco, usa óculos e utiliza-se de vários instrumentos para a criação de experimentos malucos (CHAMBERS, 1983).

Também, foi possível observar, através das anotações dos pesquisadores que foram a campo, que durante o desenvolvimento da primeira situação de aprendizagem, realizada com as crianças, quando os pesquisadores apresentam imagens pré-concebidas a respeito do conceito de cientista para elas e, em seguida, questionam: "O que é um cientista?", "O que ele faz?", "Onde eles trabalham?", "Todos nós podemos ser cientistas?", a maioria das respostas delas está relacionada com: "o cientista é o cara que faz poção", "é o que faz coisas que não existiam antes", "o cientista sempre tem ideia", "fazem coisas que só os cientistas sabem fazer", "nem todo mundo pode ser cientista". No entanto, podemos identificar por meio dessas falas, a concepçáo individualista e elitista dentro do olhar das crianças que, de certa forma, acaba transmitindo impressóes negativas, fazendo-as acreditarem que não possuem capacidade para se envolverem com questóes relacionadas ao conhecimento científico.

\section{Investigaçáo como atividade abundante}

Nesta categoria, as crianças demonstraram que compreendem a investigação como uma açáo que pode ser realizada por qualquer pessoa. Ao contrário das crianças que compóem a primeira categoria, as crianças do segundo grupo supóem que não se faz necessário ter alto índice de inteligência ou da necessidade de termos à nossa disposiçáo objetos específicos para investigar, basta ter um olhar atento e curioso perante o mundo que as cerca.

Além disso, acreditam que para encontrar as respostas de suas indagaçóes, existe todo um processo de pesquisa e de análise que precisará ser realizado. Podemos entender um pouco mais, observando o desenho a seguir. 
FIGURA 3 - Aluna da Educação Infantil.

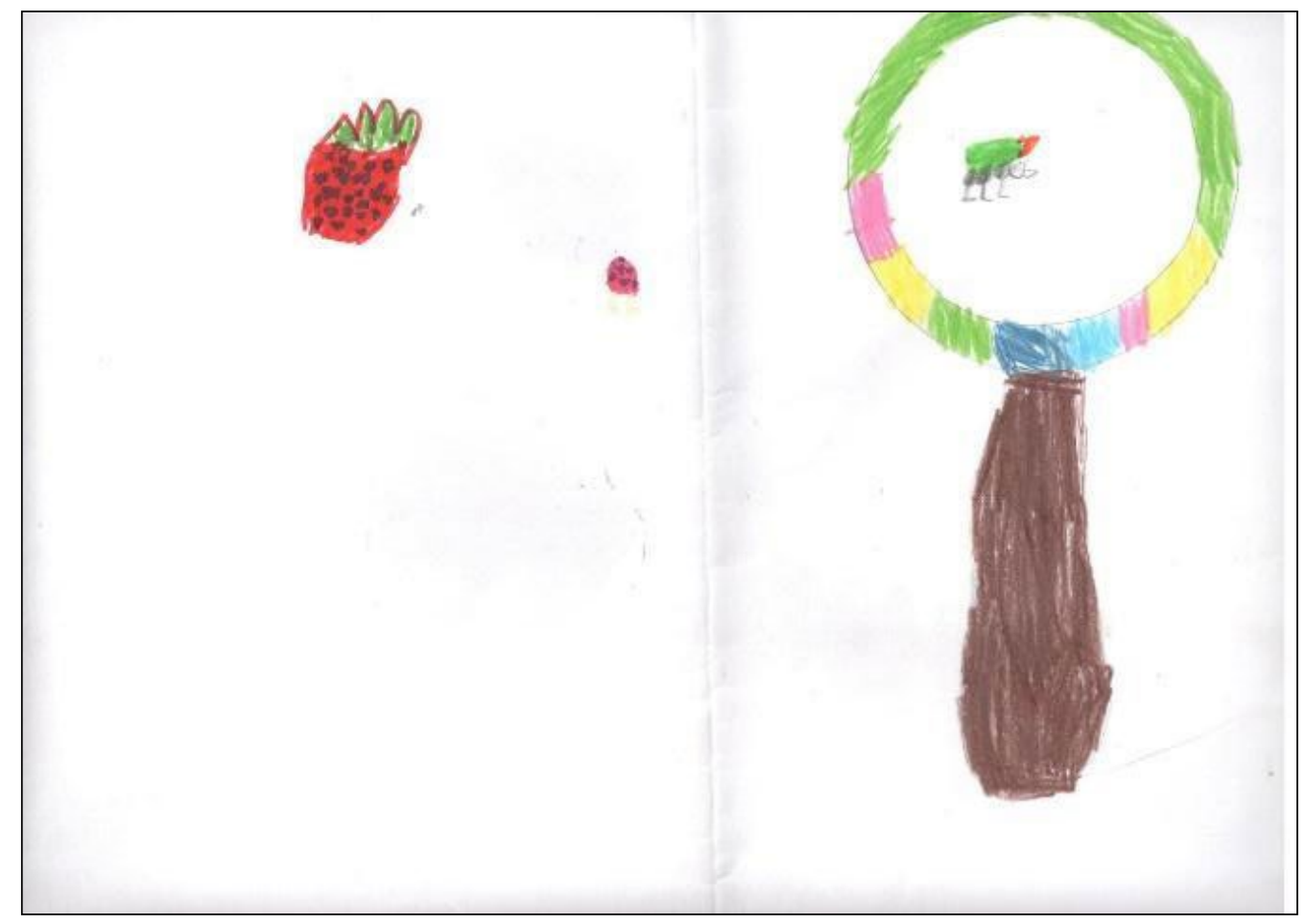

Nesse desenho, a criança apresenta uma lupa de tamanho grande e uma formiga por detrás da lente, dando a impressão que está a observar um inseto. Também ilustra outros elementos, como um moranguinho, uma joaninha, que parecem ter chamado sua atençáo durante uma das situaçóes de aprendizagem, na qual os pesquisadores levaram as crianças para investigarem a parte externa da escola, para que pudessem observar livremente o que as instiga a querer conhecer e a saber mais.

Olhando para os desenhos da figura 3, percebe-se que a criança se coloca como protagonista de sua investigaçáo, ou seja, náo desenha uma pessoa específica fazendo experimentos magníficos, mas sim, o que ela observou e explorou durante a atividade realizada. Desta forma, a aluna parece se aproximar do conhecimento científico e entender que a investigação também envolve a construção de um olhar "atento e sensível à realidade, aos múltiplos ângulos e olhares que podem ser dirigidos a ela, selecionados, registrados, lidos e reinterpretados" (KRAMER et al, 2009, p.77).

$\mathrm{Na}$ escrita criativa apresentada a seguir, também podemos observar que se coloca como participante do processo investigativo. 
FIGURA 4 - Aluna do Ensino Fundamental.

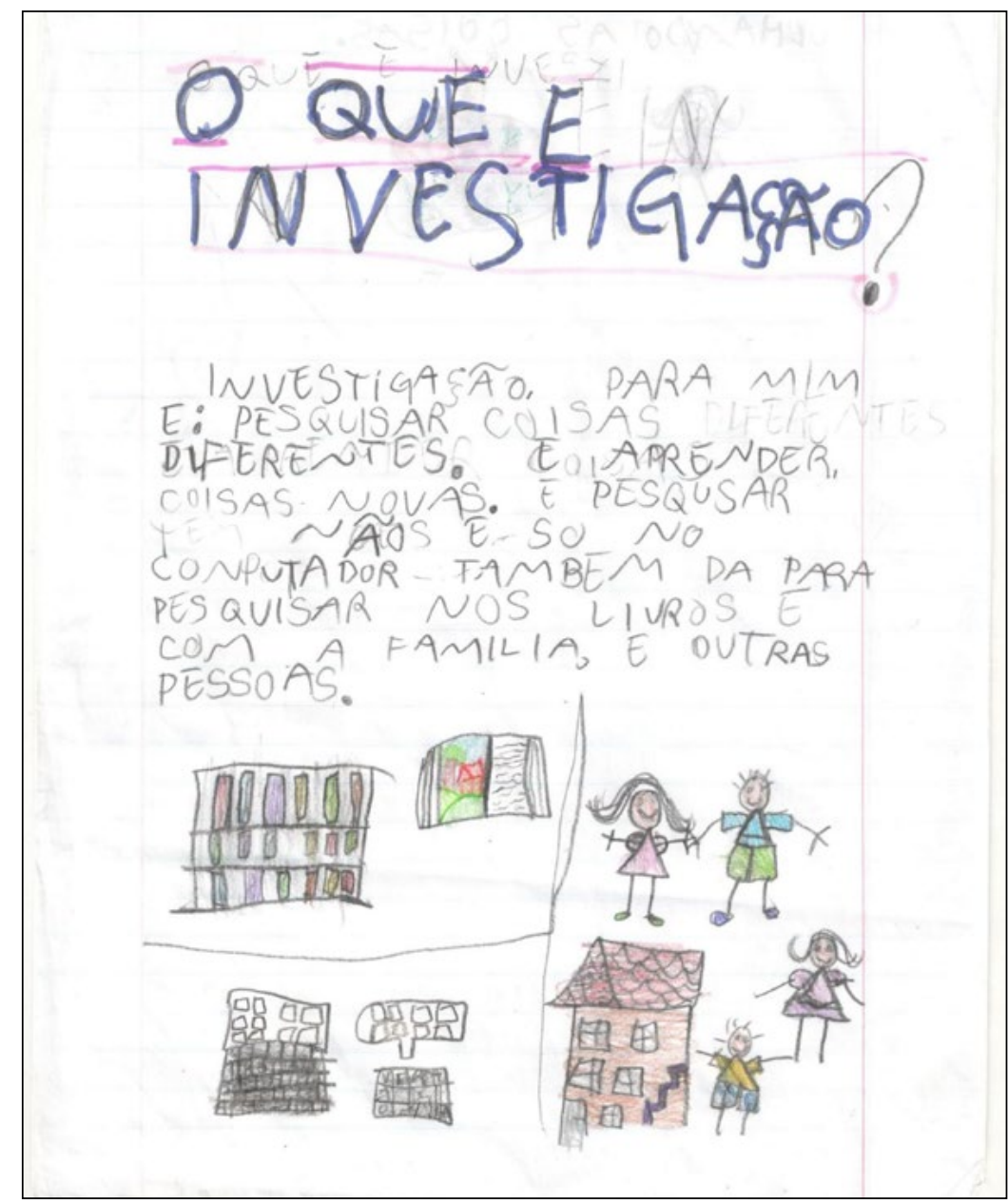

A criança demonstra ter entendido que a investigação pode ser realizada, através de diferentes modos, quando escreve que também dá para pesquisar nos livros e, com outras pessoas, quando se reporta na escrita à família. Diante do exposto podemos dizer que quando a criança passa a entender a existência do outro, a interagir com outras pessoas, tanto colegas como familiares e, também, com o meio em que está inserida, ela é percebida como protagonista (MATIAS; CAMARGO, 2018).

\section{CONSIDERAÇÓES FINAIS}

A partir da análise dos desenhos, das escritas criativas e das falas das crianças, no decorrer da pesquisa, identificamos que a realização das cinco situaçóes de aprendizagem, em que os pesquisadores que foram a campo buscaram compreender o que elas entendem por investigação e também mostrar para elas que todos nós 
podemos ser investigadores, foram extremamente relevantes, pois mudaram o olhar de algumas crianças sobre a ciência em si.

A primeira categoria foi formada por crianças que observam a investigação como uma atividade que é restrita, que só pode ser desenvolvida por pessoas muito inteligentes e que para a realização dela, também é necessário a utilização de objetos específicos. Ainda, como já visto, essa ideia trazida pelas crianças parece estar ligada a uma das visóes distorcidas da ciência, mais especificamente a visão individualista e elitista, e isso, pode ser resultado de uma educação científica que transmite através do ensino, visôes erradas da ciência (PÉREZ et al., 2001).

No entanto, para Pérez et al (1999), o ensino científico, tanto das escolas como das universidades, é concebido de uma maneira simplista, através da transmissão do conhecimento e os alunos, por sua vez, acabam não se envolvendo diretamente neste processo de construção da experiência, pois não é oferecido a eles a oportunidade de criar problemas, levantar hipóteses, identificar erros, que são etapas fundamentais para a aproximação com a aprendizagem científica.

Já a segunda categoria, é formada por crianças que compreendem a investigaçáo como uma atividade cotidiana, que pode ser realizada por qualquer pessoa. E, esse olhar das crianças parece ter sido construído em meio às situações de aprendizagem em que elas participaram do processo investigativo e viram que qualquer um pode investigar.

Desse modo, fica explícito que para acontecer uma mudança na educação científica é necessário modificar a epistemologia dos professores (BELL; PEARSON, 1992). Sendo assim, parece que se utilizar da estratégia investigativa seja uma excelente ideia para aproximar as crianças da sua aprendizagem, pois como visto na análise realizada dentro da pesquisa, através desta estratégia, as crianças sentiram-se mais ativas e integradas do seu processo de aprendizagem.

Cabe ao professor, desenvolver atividades "para e com as crianças" (SCHNEIDER, 2015, p. 17), dando cada vez mais voz a elas. Portanto, precisamos considerar o ambiente e a escuta atenta do professor para oferecermos um ensino voltado às crianças, tendo em vista os seus interesses e as suas necessidades.

Por fim, destacamos a importância que esta pesquisa teve na vida das crianças, pois através da utilização da estratégia investigativa conseguimos incentivá-las a terem um olhar mais atento perante o que as rodeia. Através da construção de um olhar mais detalhista, elas tornam-se mais curiosas e, consequentemente, questionam-se mais, estimulando-se a buscar respostas às suas próprias indagaçóes, tornando-se mais participativas e protagonistas das suas aprendizagens.

\section{REFERÊNCIAS}

BARDIN, Laurence. Análise de conteúdo. São Paulo: Ediçōes 70, 2012.

BELL, B. F; PEARSON, J. (1992). Better Learning. International Journal of Science Education, 14 (3), 349-361. 
CACHAPUZ et al. A Necessária Renovaçáo do Ensino das Ciências. Editora: Cortez, 2005.

CARNAZ, Maria Elisabete Alves Rosa. Da criatividade à escrita criativa. 2013. Tese de Doutorado.

CHAMBERS, D. W. Stereotypic Images of the Scientist: The Draw-A-Scientist Test. Science Education Assessment Instruments. John Wiley \& Sons, 1983. Disponível em: $<$ https://onlinelibrary.wiley.com/doi/abs/10.1002/sce.3730670213>. Acesso em: 04 maio. 2020.

CHEMIN, Beatris F. Manual da Univates para trabalhos acadêmicos: planejamento, elaboração e apresentação. 3. ed. Lajeado: Univates, 2015.

\section{FERRAZ, Arthur T.; SASSERON, Lúcia H. Espaço Interativo de Argumentaçáo}

Colaborativa: condiçóes criadas pelo professor para promover argumentação em aulas investigativas. Ensaio Pesquisa em Educação em Ciência. 19, Belo Horizonte, 2017. Disponível em: <https://www.scielo.br/pdf/epec/v19/1983-2117-epec-19-e2658.pdf>. Acesso em: 02 maio. 2020.

PÉREZ et al. Para uma imagem não deformada do trabalho científico. São Paulo, Ciência \& Educação, v. 7, n. 2, p. 125-153, 2001. Disponível em: <https://docente. ifrn.edu.br/mauriciofacanha/ensino-superior/disciplinas/epistemologia/artigos-e-demaistextos-para-estudo/gil-perez-et-al.-para-uma-imagem-nao-deformada-do-trabalhocientifico.-sao-paulo-ciencia-educacao-v.-7-n.-2-p.-125-153-2001/view>. Acesso em: 15 abril. 2020.

PÉREZ, D., CARRASCOSA, J., DUMAS-CARRÉ, A., FURIÓ, C., GALLEGO, N., GENÉ, A., GONZÁLEZ, E., GUISASOLA, J., MARTINEZ, J., PESSOA, A. SALINAS, J., TRICÁRICO, H. e VALDÉS, P. (1999). ¿¿Puede hablarse de consenso constructivista en la educación científica? Enseñanza de las Ciencias, 17, (3), 503-512.

KRAMER, Sonia; LEITE, Maria I.; LOPES, Ana E.; PORTO, Cristina L.; DESGRANGES, Flávio; NOGUEIRA, Letícia; CABRAL, Márcia; PEREIRA, Rita M.R.; SOUZA, Solange J. Infância e produção cultural. 8a ed. São Paulo: Papirus, 2009, p. 75-107; p. 131-150.

LORENZON, Mateus. A espiral investigativa como uma estratégia de desenvolvimento da alfabetizaçáo científica nos anos iniciais do ensino fundamental. Dissertação (Mestrado). Universidade do Vale do Taquari, Programa de Pós-Graduação em Ensino, 2018.

MATIAS, Ana Karolyne Rodrigues; CAMARGO, Gislene. Os espaços educadores na abordagem em Reggio Emilia e suas contribuiçóes para uma escola da rede privada da regiáo de Criciúma/SC. Revista Saberes Pedagógicos, v. 2, n. 2, p. 36-56, 2018. Disponível em: <http://periodicos.unesc.net/pedag/article/view/4247>. Acesso em: 10 maio. 2020. 
RINALDI, Carlina. O currículo emergente e o construtivismo social. In.: EDWARDS, C; GANDINI, L.; FORMAN, G. (orgs). As cem linguagens da criança: a abordagem de Reggio Emilia na educação da primeira infância. POA: Artmed. 1999. p. 113-122.

SILVA, Jacqueline Silva da. O planejamento no enfoque emergente: uma experiência no $1^{\circ}$ ano do Ensino Fundamental de nove anos. Tese (Doutorado). Universidade Federal do Rio Grande do Sul, Programa de Pós-graduação em Educação, 2011.

SILVA, Jacqueline Silva da; BEUREN, Jéssica; LORENZON, Mateus. Investigar com crianças: subsídios para formação e trabalho docente. Lajeado: Univates, 2016. E-book. Disponível: <https://www.univates.br/editora-univates/publicacao/166>. Acesso em: 22 fev. 2020. 